\title{
DEVELOPMENT OF AN ANTIBODY-BASED CAPTURE ENZYME-LINKED IMMUNOSORBENT ASSAY FOR DETECTING ECHINOSTOMA CAPRONI (TREMATODA) IN EXPERIMENTALLY INFECTED RATS: KINETICS OF COPROANTIGEN EXCRETION
}

\author{
Rafael Toledo, Ana M. Espert, Carla Muñoz-Antoli, Antonio Marcilla, Bernard Fried*, and J. Guillermo Esteban \\ Departamento de Parasitología, Facultad de Farmacia, Universidad de Valencia, Av. Vicente Andrés Estellés s/n, 46100 Burjassot, Valencia, \\ Spain.e-mail: rafael.toledo@uv.es
}

\begin{abstract}
The present study reports on the development of a coproantigen capture enzyme-linked immunosorbent assay (ELISA) for detecting Echinostoma caproni in experimentally infected rats. The capture ELISA was based on polyclonal rabbit antibodies that recognize excretory-secretory (ES) antigens. The detection limit of pure ES was $3 \mathrm{ng} / \mathrm{ml}$ in sample buffer and $60 \mathrm{ng} / \mathrm{ml}$ in fecal samples. The test was evaluated using a follow-up of 10 rats experimentally infected with 100 metacercariae of E. caproni, and the results were compared with those of other diagnostic methods such as parasitological examination and antibody titers determined by indirect ELISA. Coproantigens were detected in all the infected rats from the first day postinfection (DPI). The period of maximal coproantigen excretion was between 7 and 21 DPI. The values remained positive until 49-56 DPI, coinciding with the disappearance of the eggs in the stool samples of the infected rats. The kinetics of coproantigen detection were correlated with those of egg output. The present assay provides an alternative tool for the diagnosis of the echinostome infections. The proposed capture ELISA makes possible an earlier diagnosis than that provided by parasitological examination and indirect ELISA and also allows for the differentiation of past and current infections. Our results show that this assay can also be used to monitor the course of echinostome infections.
\end{abstract}

Echinostomes are intestinal trematodes with no tissue phase in the final host. Several vertebrates, such as aquatic birds and mammals, including humans (Graczyk and Fried, 1998), have been recorded as definitive hosts of echinostomes. Echinostomiasis in vertebrate hosts has been usually diagnosed by the presence of eggs in stool samples. However, this procedure is tedious, and eggs are not always present in feces because the worms may be preovigerous or mature worms may not be voiding eggs. Moreover, parasite maturation and egg production patterns may vary depending on different factors such as worm crowding or host species (Huffman and Fried, 1990; Toledo et al., 2003). Earlier studies have demonstrated that immunodiagnosis of echinostome infections is feasible by indirect enzyme-linked immunosorbent assay (ELISA) using different antigenic extracts. Agger et al. (1993) showed that anti-Echinostoma caproni antibodies are detectable in sera from experimentally infected NMRI mice by the 14th day postinfection (DPI) by using crude adult antigen. Graczyk and Fried (1994, 1995) detected anti-E. caproni immunoglobulins by 8 DPI in ICR mice by using glycocalyx membrane crude antigen from adult worms. However, the application of serologic diagnosis has major limitations, particularly in laboratory animals. For example, antibody titers persist after worm loss and also depend on the host species (Simonsen et al., 1991; Toledo et al., 2003). Moreover, animal handling to obtain a sufficient amount of serum samples is often difficult. These factors justify the need for alternative tools for the diagnosis of echinostomiasis both in natural and in experimental infections.

Coproantigen capture ELISA provides an early and specific diagnosis of trematode infections in humans and animals (Espino et al., 1997, 1998; Doumenigo et al., 1999). The main advantages are that coproantigens are detected earlier than antibodies and this assay detects current infection only. In the present article, we describe a polyclonal antibody-based capture ELISA for the immunological detection of excretory-se-

Received 3 February 2003; revised 1 May 2003; accepted 1 May 2003.

* Department of Biology, Lafayette College, Easton, Pennsylvania 18042. cretory (ES) coproantigens of E. caproni in experimentally infected rats. We have also compared the results obtained with those of other diagnostic methods such as parasitological examination of feces and indirect ELISA to evaluate the usefulness of the method described herein for diagnosis and monitoring of echinostome infections.

\section{MATERIALS AND METHODS}

\section{Parasites and experimental infections}

The strain of E. caproni has been described previously by Fujino and Fried (1993). Encysted metacercariae of E. caproni were removed from the kidneys and pericardial cavities of experimentally infected Biomphalaria glabrata and used to infect rats. Ten outbred male albino rats (Wistar) weighing 110-150 g were each infected, via a stomach tube, with 100 metacercariae of E. caproni. Five 110- to 150 -g rats were left uninfected and used as controls. All the animals were maintained under conventional conditions with food and water ad libitum. At 84 DPI, the rats were necropsied, and the number of worms recovered per rat was recorded.

\section{ES antigens}

To obtain ES antigens of E. caproni, we followed the methodology described by Toledo et al. (2003). Adult worms were collected from the intestines of rats $4 \mathrm{wk}$ after experimental infection with 100 metacercariae of E. caproni. After thorough washings with phosphate-buffered saline (PBS, $\mathrm{pH}$ 7.4), the adult worms were maintained in medium at concentrations of 10 worms $/ \mathrm{ml}$ for $12 \mathrm{hr}$ at $37 \mathrm{C}$ in PBS containing 0.8 $\mathrm{mM}$ phenylmethylsulfonyl fluoride (Sigma, St. Louis, Missouri), $100 \mathrm{U}$ penicillin (Sigma), and $100 \mu \mathrm{g} / \mathrm{ml}$ streptomycin (Sigma). The medium was collected and centrifuged at $15,000 \mathrm{~g}$ for $30 \mathrm{~min}$ at $4 \mathrm{C}$, and the supernantant was collected. The protein content was measured by the Bio-Rad (Hercules, California) protein assay and adjusted to $1 \mathrm{mg} / \mathrm{ml}$ using an ultrafiltration membrane (YM-3, Millipore, Bellerica, Massachusetts). The antigens were stored at $-20 \mathrm{C}$ until use.

\section{Fecal and serum samples}

Fecal samples were collected from each rat just before the experimental infection and daily during the first week postinfection (PI) and weekly from 7 to 84 DPI. Fecal samples were examined to determine the number of eggs per gram of feces (EPG), as described in previous studies (Toledo et al., 2003). Briefly, 24-hr fecal productions were collected from each animal and weighed individually. The individual samples were emulsified at $1 \mathrm{~g} / 30 \mathrm{ml}$ in a solution of $0.1 \mathrm{M} \mathrm{NaOH}$. The mixture was shaken at room temperature (RT) for $2 \mathrm{hr}$ and the sediment resuspended in $2 \mathrm{ml}$. The eggs contained in $200 \mu \mathrm{l}$ were counted. Five 
replicated samples were analyzed for each day and animal to determine the EPG, and the average $\pm \mathrm{SD}$ was calculated for each week of the experiment.

Fecal eluates for coproantigen detection were prepared as described by Espino et al. (1997), with some modifications. Briefly, $1 \mathrm{~g}$ of fresh feces from individual specimens was suspended in $3 \mathrm{ml}$ of PBS containing $0.05 \%$ Tween 20 (PBST). These suspensions were centrifuged at $900 \mathrm{~g}$ for $30 \mathrm{~min}$. The supernatants were filtered using a $0.20-\mu \mathrm{m}-$ pore size membrane (Nalge Nunc, Naperville, Illinois) and collected to measure coproantigens.

Blood was collected weekly from each infected and control rat by cardiac puncture under anesthesia. After clotting of the blood overnight at $4 \mathrm{C}$, serum was separated from the clot by centrifugation. The supernantant fecal eluates and the serum samples were stored at $-20 \mathrm{C}$ until use.

\section{Polyclonal IgG anti-E. caproni ES antigens}

Polyclonal IgG anti-E. caproni ES antigens were obtained by inoculating two 3-kg New Zealand white rabbits with ES trematode products. Three hundred micrograms of ES antigen was emulsified in 0.3 $\mathrm{ml}$ of Freund complete adjuvant and used to hyperimmunize each rabbit by giving several inoculations. Rabbits were given similar inoculations on 4 dates, at 2-wk intervals, using Freund incomplete adjuvant. Blood was drawn 21 days after the final inoculation. Serum was pooled, and the anti-E. caproni ES antigen globulins containing IgG were obtained by precipitation with $50 \%$ ammonium sulfate and then dialyzed extensively against PBS.

\section{Biotinylation of anti-E. caproni antibodies}

Antibodies against ES products of E. caproni were biotinylated as described by Harlow and Lane (1988). Briefly, the antibody solution was adjusted to $3 \mathrm{mg} / \mathrm{ml}$ and mixed with a $1 \%$ solution of biotin succinimide ester (Sigma) in anhydrous dimethyl sulfoxide (Panreac, Barcelona, Spain) at $80 \mu \mathrm{g}$ of biotin per milligram of antibody. The solution was incubated and rotated for $4 \mathrm{hr}$ at RT. The uncoupled biotin was removed by extensive dialysis against PBS.

\section{Indirect ELISA}

The presence of antibodies against ES antigens of E. caproni was determined by indirect ELISA as described by Toledo et al. (2003), with some modifications. Polystyrene microtiter plates (Nalgene, Naperville, Illinois) were coated overnight at $4 \mathrm{C}$ with $100 \mu \mathrm{l} /$ well of a $30-\mu \mathrm{g} / \mathrm{ml}$ solution of ES antigens of E. caproni in $0.1 \mathrm{M}$ carbonatecoating buffer, $\mathrm{pH}$ 9.6. The plates were washed 3 times with PBST. Uncoated sites were blocked with 5\% nonfat dry milk in PBST. After incubation for $1 \mathrm{hr}$ at $37 \mathrm{C}$, the plates were emptied, and $100 \mu \mathrm{l}$ of diluted serum (1:400 in PBST) was dispensed into each well. The plates were incubated for $2 \mathrm{hr}$ at RT and then washed 5 times with PBST. One hundred microliters of horseradish peroxidase-conjugated goat anti-rat IgG (ICN Biomedicals, Aurora, Ohio) diluted 1:3,000 in PBS was added into each well and incubated for $2 \mathrm{hr}$ at RT. The plates were washed as described above, and $100 \mu \mathrm{l}$ of the substrate solution (10 $\mu$ l hydrogen peroxide, $30 \% \mathrm{w} / \mathrm{v}+25 \mathrm{ml}$ of $0.1 \mathrm{M}$ citrate buffer, $\mathrm{pH} 5.0+10 \mathrm{mg}$ $o$-phenylenediamine hydrochloride) was added and incubated in the dark at RT. The enzyme reaction was stopped with $50 \mu l$ of $3 \mathrm{~N} \mathrm{HCl}$ per well. The plates were read at $492 \mathrm{~nm}$ in a Bio-Rad 550 microplate ELISA reader.

\section{Polyclonal antibody-based capture ELISA}

Polyestyrene microtiter plates (Nalgene) were sensitized overnight at $4 \mathrm{C}$ with $100 \mu \mathrm{l}$ per well of unlabeled anti-E. caproni antibodies at a concentration of $30 \mu \mathrm{g} / \mathrm{ml}$ in $0.1 \mathrm{M}$ carbonate buffer, $\mathrm{pH}$ 9.6. They were then washed 3 times with PBST, and the unbound sites were blocked with $5 \%$ nonfat dry milk diluted in PBST. After incubation for $1 \mathrm{hr}$ at $37 \mathrm{C}$, the plates were emptied by aspiration. One hundred microliters of undiluted fecal eluates were added, and the plates were incubated for $2 \mathrm{hr}$ at RT; thereafter, they were washed 5 times with PBST. One hundred microliters of biotinylated anti-E. caproni antibody, diluted 1 : 2,000 in PBST, was added to each well and incubated for $2 \mathrm{hr}$ at RT, after which it was washed 5 times as described above. One hundred microliters of labeled streptavidin-peroxidase (Sigma), diluted 1:5,000

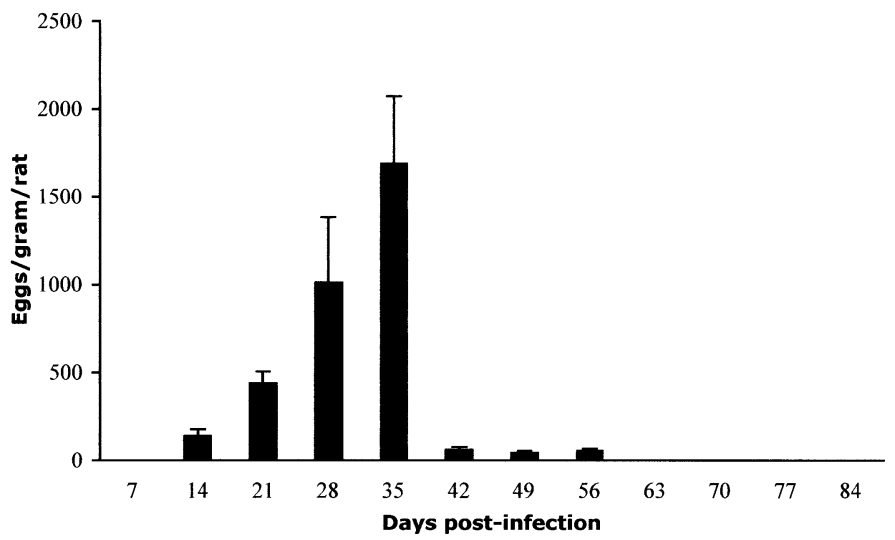

FIGURE 1. Mean EPG in rats experimentally infected with 100 metacercariae of Echinostoma caproni each week during the experiment. Vertical bars represent the SD.

in PBS, was added to each well and incubated for $2 \mathrm{hr}$ at RT. The plates were washed as above, and 100 microliters of the substrate solution was added and incubated in the dark at RT. The enzyme reaction was stopped with $50 \mu \mathrm{l}$ of $3 \mathrm{~N} \mathrm{HCl}$ per well. The plates were read spectrophotometrically at $492 \mathrm{~nm}$ as above.

\section{Statistical analysis}

Each ELISA assay was performed in triplicate, and the absorbance readings from wells with the same sample were expressed as the mean \pm SD. The cutoff for each ELISA was defined as the mean of the samples from the control rats +3 SD. The difference between the optical density (OD) values for the infection and control specimens at each point in time was calculated and tested using Student's $t$-test. The correlation between the ES concentration in the spiked samples and the capture ELISA values was analyzed by the Pearson product moment correlation test. For correlation of the egg counts and capture ELISA values from 7 to $84 \mathrm{DPI}$, the Spearman nonparametric correlation test was used; $P<0.05$ was considered as significant.

\section{RESULTS}

\section{Development of the infection}

All the rats experimentally exposed to 100 metacercariae of E. caproni became infected. The duration of the prepatent period was highly homogeneous. Egg release began at 10-12 $(11.11 \pm 0.63)$ DPI. The kinetics of egg release was monitored during the first 84 DPI (Fig. 1). The egg release progressively increased during the first $5 \mathrm{wk}$ of the infection, to reach a maximum at 35 DPI in all the rats. Thereafter, the EPG values suddenly declined. Eight $(80 \%)$ of the rats were negative to egg examination at 49 DPI, whereas the other $2(20 \%)$ remained positive until 56 DPI. From 63 DPI until the end of the experiments, all the samples were negative. No adult worm was detected at necropsy of the animals at 84 DPI.

\section{Antibody titers}

Antibody titers against ES antigens of E. caproni in the experimentally infected rats were investigated by indirect ELISA. The results showed that rats develop only a weak antibody response against E. caproni ES antigens (Fig. 2). Moreover, the antibody levels varied widely between individual infections. The cutoff point differentiating negative from positive sera was an OD value of 0.301. Antibodies to E. caproni ES antigens were detected in $3(30 \%)$ of the infected rats at 42 DPI. At 49 


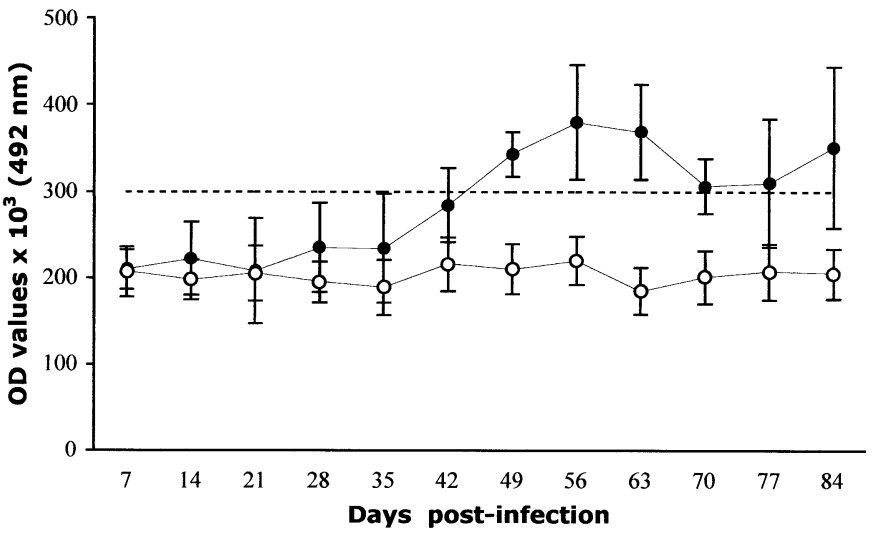

FIGURE 2. Detection of antibodies to Echinostoma caproni excretory-secretory antigens by indirect ELISA. Mean OD values of control (O) and infected (O) rats during the course of the experiment. (-) Cutoff point is defined as the mean OD value of the controls $+3 \mathrm{SD}$. Vertical bars represent the SD.

DPI all the infected animals were positive to indirect ELISA. Antibody levels became stable from 49 to 63 DPI. However, 4 $(40 \%)$ of the infected rats reverted to negative values at 70 DPI, whereas the other $6(60 \%)$ remained positive until the end of the experiment. The mean OD value during the complete course of the experiment in all the infected rats was $0.285 \pm 0.062$, whereas the maximum OD value $(0.381 \pm 0.066)$ was observed at 56 DPI. Statistically significant differences $(P<0.05)$ between sera from control and infected rats were observed in each sample analyzed from 49 DPI until the end of the experiment.

\section{Detection limits of the capture ELISA}

The detection limits of the capture ELISA were determined by measuring serial dilutions of E. caproni ES antigen in sample buffer and fecal extracts from rats naive for helminths. The final concentration of ES antigen in the sample buffer or the spiked fecal extracts ranged from 0.001 to $250 \mu \mathrm{g} / \mathrm{ml}$. The samples were then tested in triplicate to the capture ELISA. The detection limit of ES antigen was $3 \mathrm{ng} / \mathrm{ml}$ in sample buffer and $60 \mathrm{ng} / \mathrm{ml}$ in fecal extracts. A significant positive correlation was found between the OD values and the final concentration of ES antigen in the sample buffer $\left(r_{p}=0.93, \mathrm{n}=20, P<0.001\right)$ and the fecal extract $\left(r_{p}=0.89, \mathrm{n}=20, P<0.001\right)$.

\section{Kinetics of $E$. caproni coproantigen excretion}

The kinetics of the coproantigen excretion in rats experimentally infected with E. caproni was followed daily during the first week of the infection and weekly from 7 to 84 DPI (Fig. 3 ). The cutoff value for this technique, calculated as described above, was 0.200 .

In all the infected rats, the coproantigen levels showed a characteristic and consistent pattern over time. The mean OD value in the infected rats over time was $0.263 \pm 0.104$. All the samples analyzed were positive from the first DPI to 49 DPI. The $t$-test showed significant differences $(P<0.05)$ between the OD values from the infected and the control rats in each sample from 1 until 49 DPI. Antigens of E. caproni were detectable in the feces of all infected rats from 1 DPI. Infected animals showed time-dependent changes in coproantigen levels

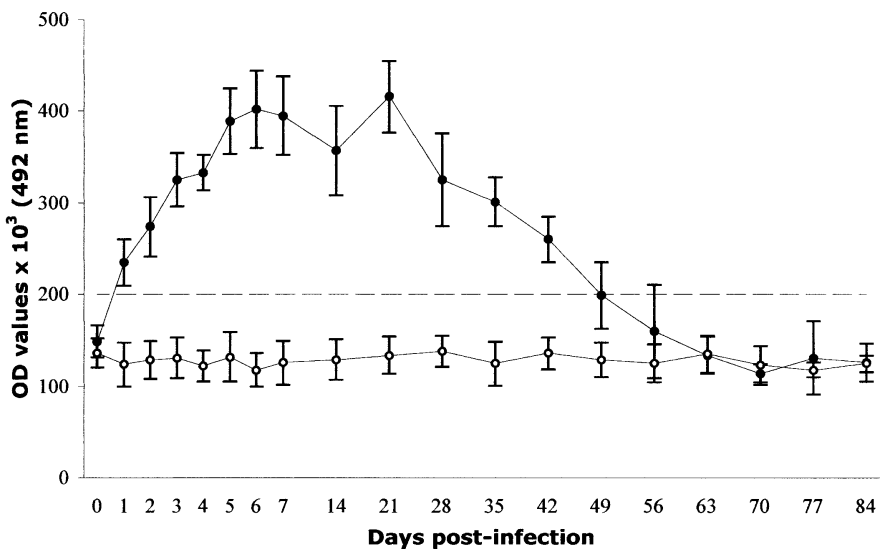

FIGURE 3. Detection of Echinostoma caproni excretory-secretory antigens in feces of experimentally infected rats. Mean OD values of control $(\bigcirc)$ and infected $(O)$ rats during the course of the experiment. $(-)$ Cutoff point is defined as the mean OD value of the controls +3 SD. Vertical bars represent the SD.

(Fig. 3). The first days of the infection were characterized by a progressive increase in the ELISA values, reaching a period of maximal coproantigen excretion between 7 and 21 DPI. The coproantigen maximal response was observed at 21 DPI $(0.421$ $\pm 0.039)$, just before the period of maximal egg output. Thereafter, the OD values suddenly declined. From this day onward the OD values progressively decreased. In $8(80 \%)$ of the infected rats, the OD values were positive until 49 DPI, whereas in the other $2(20 \%)$, they remained positive until 56 DPI. The latter animals were those that remained positive to egg examination until 56 DPI. From this day onward all the samples analyzed were negative. A significant correlation between the absorbance values and the egg output in the infected rats from 7 DPI until the end of the experiment was found $\left(r_{s}=0.67, \mathrm{n}=\right.$ $12, P<0.05)$.

\section{DISCUSSION}

The present study reports the development of a polyclonal antibody-based capture ELISA for detecting ES antigens of $E$. caproni in fecal samples of experimentally infected rats. The results demonstrate for the first time that the immunological detection of ES antigens of echinostomes in fecal samples is feasible from the first day after infection. In contrast, parasitological diagnosis is likely only by $10-12$ DPI, and antibodies against E. caproni ES antigens are detectable only from 42-49 DPI by indirect ELISA. The detection limit of the present assay is high, with a detection capacity of $3 \mathrm{ng} / \mathrm{ml}$ in sample buffer and $60 \mathrm{ng} / \mathrm{ml}$ in fecal samples. The difference in the detection limit when diluting ES antigens in sample buffer or fecal samples indicates that the presence of fecal material interferes with the antigen detection method. However, the differences in the OD values observed between the samples from the infected and the uninfected control rats were of sufficient magnitude to determine the presence of ES antigens.

Diagnosis and monitoring over time of echinostome infections have been typically done by finding eggs in fecal samples, although the difficulties entailed in the parasitological procedures gave rise to the need for development of immunological methods of diagnosis (Graczyk and Fried, 1994). However, only 
a limited number of studies have considered this topic, and only indirect ELISA methods have been developed (Simonsen et al., 1991; Agger et al., 1993; Graczyk and Fried, 1994, 1995; Toledo et al., 2003). These studies have demonstrated that antiE. caproni immunoglobulins can be detected in experimentally infected mice by 14 and 8 DPI depending on the antigen used (Agger et al., 1993; Graczyk and Fried, 1994, 1995). Moreover, antibody detection methods have major limitations, i.e., the presence of antibodies indicates previous exposures rather than active infections, and considerably different patterns of anti-E. caproni antibody titers have been observed depending on the host species (Simonsen et al., 1991; Toledo et al., 2003). In the current study, detectable levels of antibodies were obtained only from 42-49 DPI, when the animals were free of parasites by parasitological criteria. Moreover, according to our results, rats seem to develop a weaker antibody response to E. caproni than mice. All these facts show that the utility of serologic diagnosis in echinostome infections is limited and alternative tools may be needed.

The coproantigen capture ELISA developed herein provides a rapid and sensitive diagnosis of an echinostome infection. The main advantages of the present assay over other diagnostic methods are that coproantigens are detected earlier than eggs (1 DPI vs. 10-12 DPI) and antibodies (1 DPI vs. 42-49 DPI) and that the present assay does not depend on the capacity of the host to develop antibody response. Other advantages of the present assay are that fecal samples are collected and hence avoid animal handling and possible damage for serum collection and a large number of animals can be screened without time-consuming parasitological examination procedures.

The use of coproantigen detection has been already successfully demonstrated for other trematodes such as Fasciola hepatica (Espino et al., 1997; Abdel-Rahman et al., 1998; Doumenigo et al., 1999; Almazan et al., 2001). However, the kinetics of coproantigen excretion is clearly different from that observed for E. caproni in relation to the respective life cycles. In $F$. hepatica infections, coproantigens are first detected approximately 4-6 wk PI, coinciding with the arrival of most of the flukes in the bile ducts and the subsequent release of the ES products to the bile. In contrast, echinostomes are intestinal digeneans with no tissue phase. Consequently, ES products are released in the feces immediately after metacercarial excystment, and coproantigens are detected from the first DPI. The first days of infection are characterized by a progressive increase of coproantigen excretion. This is probably related to a period of high activity of the newly excysted metacercaria and juvenile adult worms. Further analysis of the products released in the first days of the infection may be of great interest because they could be involved in host-parasite interactions such as habitat location and establishment within the intestine and even in chemical communication and mate attraction. The presence of enzymes associated with excretory concretions in the metacercariae of E. caproni may be involved in some of these events as previously noted (Ursone and Fried, 1995).

We have found a significant degree of correlation between the capture ELISA values and the egg output from 7 DPI until the end of the experiment. The detection of coproantigen is maximal from 7 to $21 \mathrm{DPI}$, immediately preceding the period of maximal egg output. The high degree of coproantigen excretion during this period may be attributed to progressive growth and maturation of the adult worms associated with a higher metabolic rate and increased shedding of surface antigens (Andresen et al., 1989). A parallel decrease of coproantigen release and egg output was observed, probably in relation to the decrease of the worm burden. Considering all the infected animals, coproantigen mean values were negative from 56 DPI until the end of the experiment. However, it is worth mentioning that at 56 DPI, 2 of the rats were still positive to capture ELISA and egg examination. These animals simultaneously reverted to negative values for both analyses at 63 DPI. Considering all these facts, the present assay may be a useful method for monitoring the course of the echinostome infections over time.

In summary, we have developed a polyclonal antibody-based capture ELISA to detect coproantigen in rats experimentally infected with E. caproni, providing a sensitive and rapid diagnostic tool. The present assay has allowed us to describe for the first time the kinetics of coproantigen excretion in an echinostome infection. Coproantigens are detected from the first DPI, and their excretion is correlated with the egg output. This makes this method a suitable tool to follow and analyze the course of echinostome infections.

\section{ACKNOWLEDGMENTS}

The present study was supported by Spanish DGICYT project BOS2000-0570-C02-02 from the Ministerio de Educación, Cultura y Deportes, Madrid, Spain. This work was carried out while the second author (A.M.E.) was a recipient of a predoctoral fellowship from the Ministerio de Educación. The authors wish to thank I. Carpena (University of Valencia) for her assistance. This research complies with the current laws for animal health research in Spain.

\section{LITERATURE CITED}

Abdel-Rahman, S. M., K. L. O’Reilly, and J. B. Malone. 1998. Evaluation of a diagnostic monoclonal antibody-based capture enzymelinked immunosorbent assay for detection of a 26- to 28-kd Fasciola hepatica coproantigen in cattle. American Journal of Veterinary Research 59: 533-537.

Agger, M. K., P. E. Simonsen, and B. J. Vennervald. 1993. The antibody response in serum, intestinal wall and intestinal lumen of NMRI mice infected with Echinostoma caproni. Journal of Helminthology 67: 169-178.

Almazan, C., G. Avila, H. Quiroz, F. Ibarra, and P. OchoA. 2001. Effect of parasite burden on the detection of Fasciola hepatica antigens in sera and feces of experimentally infected sheep. Veterinary Parasitology 97: 101-112.

Andresen, K., P. E. Simonsen, B. J. Andersen, And A. Birch-AnderSEN. 1989. Echinostoma caproni in mice: Shedding of antigens from the surface of an intestinal trematode. International Journal for Parasitology 19: 111-118.

Doumenigo, B. E., A. M. Espino, C. M. Finley, And M. Mezo. 1999 Kinetics of antibody-based antigen detection in serum and faeces of sheep experimentally infected with Fasciola hepatica. Veterinary Parasitology 86: 23-31.

Espino, A. M., A. DíAz, A. Pérez, And C. M. Finlay. 1998. Dynamics of antigenemia and coproantigens during a human Fasciola hepatica outbreak. Journal of Clinical Microbiology 36: 2723-2726.

- , R. MARCET, AND C. M. Finlay. 1997. Fasciola hepatica: Detection of antigenemia and coproantigens in experimentally infected rats. Experimental Parasitology 85: 117-120.

FuJINO, T., AND B. FRIED. 1993. Expulsion of Echinostoma trivolvis (Cort, 1914) Kanev, 1985 and retention of E. caproni Richard, 1964 (Trematoda: Echinostomatidae) in C3H mice: Pathological, ultrastructural, and cytochemical effects on the host intestine. Parasitology Research 33: 286-292.

GrACZYK, T. K., AND B. FRIED. 1994. ELISA method for detecting antiEchinostoma caproni (Trematoda) antibodies in experimentally infected ICR mice. Journal of Parasitology 80: 544-549. 
1995. An ELISA for detecting anti-Echinostoma trivolvis (Trematoda) immunoglobulines in experimentally infected ICR mice: Cross reactivity with Echinostoma caproni. Parasitology Research 81: 710-712.

, AND - 1998. Echinostomiasis: A common but forgotten food-borne disease. American Journal of Tropical Medicine and Hygiene 58: 501-504.

Harlow, E., AND D. LANE. 1988. Antibodies: A laboratory manual. Cold Spring Harbor Laboratory, Cold Spring Harbor, New York, $726 \mathrm{p}$.

HufFMAn, J. E., AND B. FRIED. 1990. Echinostoma and Echinostomiasis. Advances in Parasitology 29: 215-269.
Simonsen, P. E., B. B. Estambale, And M. Agger. 1991. Antibodies in the serum of golden hamsters experimentally infected with the intestinal trematode Echinostoma caproni. Journal of Helminthology 65: 239-247.

Toledo, R., A. Espert, I. Carpena, C. Muñoz-Antoli, and J. G. EsTEBAN. 2003. An experimental study of the reproductive success of Echinostoma friedi (Trematoda: Echinostomatidae) in the golden hamster. Parasitology 126: 433-441.

URSONE, R. L., AND B. FRIED. 1995. Light and scanning electron microscopy of Echinostoma caproni (Trematoda) during maturation in ICR mice. Parasitology Research 81: 45-51. 